
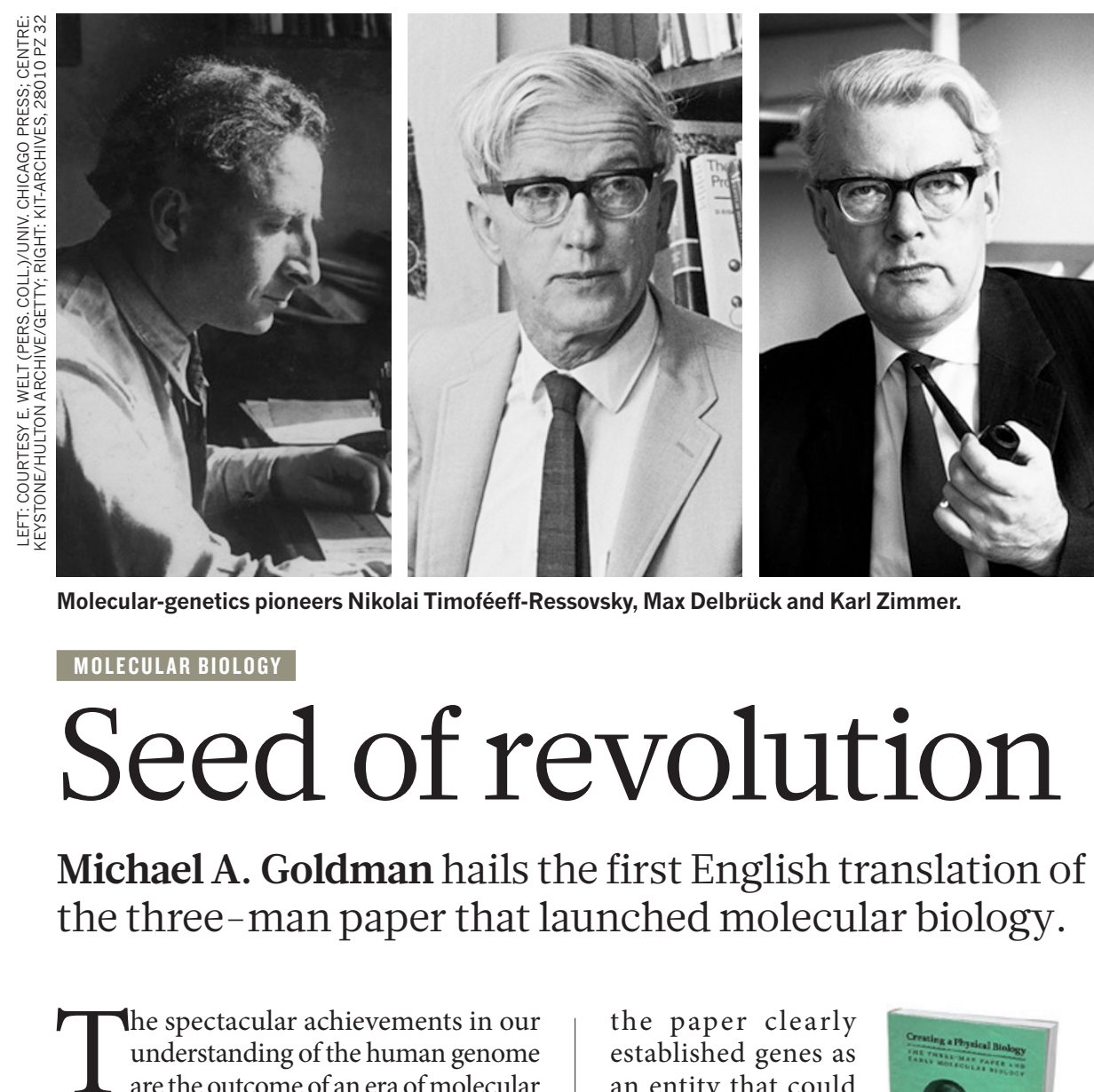

Molecular-genetics pioneers Nikolai Timoféeff-Ressovsky, Max Delbrück and Karl Zimmer.

\title{
OLECULAR BIOLOGY
}

\section{Seed of revolution}

\section{Michael A. Goldman hails the first English translation of the three-man paper that launched molecular biology.}

$\mathrm{T}$ he spectacular achievements in our understanding of the human genome are the outcome of an era of molecular biology that dates back to the 1930s. The seed was a 1935 collaboration in Germany between a theoretical physicist, a radiation physicist and a Drosophila geneticist - Max Delbrück, Karl Zimmer and Nikolai TimoféeffRessovsky, respectively. Their 'three-man paper', which sets out the interdisciplinary basis for studying the molecular nature of the gene, was revolutionary.

But this revolution burned with a slow fuse. The paper, 'On the nature of gene mutation and gene structure' was published in an obscure journal at the University of Göttingen. The manuscript had little influence until physicist Erwin Schrödinger drew heavily on it for his popular lectures, collected in his book What Is Life? published in 1944.

More than 75 years after it first appeared, the groundbreaking paper appears in English for the first time in Creating a Physical Biology. Edited by philosophers of science Phillip Sloan and Brandon Fogel, the volume also contains commentary by historians and philosophers of biology on the paper's genesis and place in history.

As Sloan and Fogel point out, the detail of the three-man paper's findings no longer holds up. But, written at a time when DNA's role in the transmission of genetic information was not understood,

\section{DNATURE.COM}

For more on early molecular genetics:

go.nature.com/qdiihy the paper clearly established genes as an entity that could be studied using the rigorous methods of physical science. This molecular approach to genetics would lead to the sequencing of the human genome.

The three authors combined their understanding of X-rays and mutation into a coherent picture of the gene. They recognized its molecular basis, stating "we view the gene

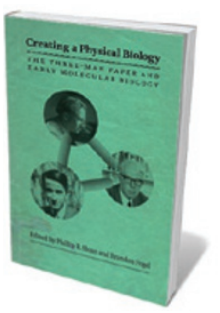

Creating a Physical Biology: The Three-Man Paper and Early Molecular Biology EDITED BY PHILLIPR. SLOAN AND BRANDON FOGEL

Univ. Chicago Press: 2011. 320 pp. $\$ 35$

as an assemblage of atoms within which a mutation can proceed as a rearrangement of atoms or dissociation of bonds".

These ideas emerged as Nazism was rising in Germany; the Jewish scientific community lived in fear of academic purges. Many key meetings between physicists and biologists took place not at universities but at Delbrück's house in Grunewald and TimoféeffRessovsky's apartment in Berlin. Such covert encounters had a pressure-cooker effect.

Meanwhile, quantum ideas were permeating the physical sciences, and Danish physicist Niels Bohr's interpretation of them had taken Copenhagen by storm. Bohr's 1932 lecture 'Light and life' probably prompted Delbrück, who studied theoretical physics under him, to turn to biology.

Bohr thought that the wave-particle duality of light was part of a general principle of complementarity in physics, in which two phenomena arising from different experimental conditions, or parallel explanations, are needed for understanding. He felt biology was the same, sensing that the vitalistic aspect of life and its physical and chemical aspect are both key to comprehending the whole.

Delbrück took this one step farther in his search for biological complementarity something beyond reductionism that molecular genetics could not explain. Paradoxically, he sought it by hammering away at gene replication, one of the most reductionist paradigms ever to hit mainstream biology. When it looked like everything in genetics was going to yield to physical explanation, he moved on to different turf: more complex physiological networks. His hopes for complementarity were dashed, yet his work drew the attention of dozens of physicists to the new biology.

The paper's logic and thoroughness cannot hide the (still unresolved) struggle to understand the complex nature of life. The authors stuck to genetics to avoid "methodologically questionable conclusions" from fields such as developmental physiology. They recognized that the mapping of genotype to phenotype was tenuous, a gap that has yet to be closed.

The contemporary contributions to Creating a Physical Biology smack of historians and philosophers of science talking to one another, and for the most part agreeing. Gino Segre's Ordinary Geniuses (Viking, 2011), among other books, gives more of scientists' perception of the science of the times.

Sloan and Fogel argue that Schrödinger's What Is Life? misrepresents the three-man paper. They note, for instance, that he misleads by saying that quantum mechanics makes possible "a complete reduction of biological to physical systems", which the paper never claims. Schrödinger also ignores its reservations about mapping genotype to phenotype. But there is little evidence that he intended to provide an authentic account.

Most scientists I asked, young and old, knew of Delbrück's role in the origins of physical biology. Not one had heard of the three-man paper. Yet the work anticipates some of today's cutting-edge science.

Interdisciplinary research remains tenuous. Delbrück wrote to Bohr that biologists have difficulty understanding "a new subtle thought". Such attitudes between disciplines have barely altered. But there is still that edge between known and unknown, the still-elusive theory of everything, and still time for paradigm shifts. This intriguing book gives us insight into how such shifts may happen.

Michael A. Goldman is a geneticist at San Francisco State University, California 94132, USA.e-mail:goldman@sfsu.edu 